University of Nebraska - Lincoln

DigitalCommons@University of Nebraska - Lincoln

Nutrition and Health Sciences -- Faculty

Publications

Nutrition and Health Sciences, Department of

$6-2010$

\title{
Validation of Nutrition Standardized Language-Next Steps
}

\author{
Paula Ritter-Gooder \\ University of Nebraska-Lincoln \\ Nancy M. Lewis \\ University of Nebraska--Lincoln, nlewis2@unl.edu
}

Follow this and additional works at: https://digitalcommons.unl.edu/nutritionfacpub

Part of the Dietetics and Clinical Nutrition Commons

Ritter-Gooder, Paula and Lewis, Nancy M., "Validation of Nutrition Standardized Language-Next Steps" (2010). Nutrition and Health Sciences -- Faculty Publications. 7.

https://digitalcommons.unl.edu/nutritionfacpub/7

This Article is brought to you for free and open access by the Nutrition and Health Sciences, Department of at DigitalCommons@University of Nebraska - Lincoln. It has been accepted for inclusion in Nutrition and Health Sciences -- Faculty Publications by an authorized administrator of DigitalCommons@University of Nebraska - Lincoln. 


\title{
Validation of Nutrition Standardized Language-Next Steps
}

\author{
Paula Ritter-Gooder, PhD, RD, LMNT \\ Nancy M. Lewis, PhD, RD, FADA
}

Paula Ritter-Gooder is a research assistant, and Nancy M. Lewis is a professor in the Department of Nutrition and Health Sciences, University of Nebraska-Lincoln.

To provide a model for quality care and outcomes management, the Nutrition Care Process (NCP) and standardized language were introduced in 2003 by the American Dietetic Association (ADA).

The standardized language, published in the International Dietetics \& Nutrition Terminology (IDNT) Reference Manual: Standardized Language for the Nutrition Care Process (1), is designed to facilitate communication, improve care, and close the gap in health care quality (2). When registered dietitians (RDs) are oriented to a nutrition care process, improvement in their documentation of nutrition care occurs (3). Since the introduction of the NCP and standardized language, RDs and dietetic technicians, registered (DTRs), have begun to adopt the process and language into their practice $(4,5)$. This article explains why validation of the standardized language is needed to make the language accurate and meaningful for practice and describes how validation is conducted using RDs.

\section{Origins of the Standardized Language}

The standardized language consists of terms describing all NCP steps; assessment, diagnosis, intervention, and monitoring and evaluation. Nutrition diagnostic terms were the first language identified using concept analysis, a critical first step in language development (Figure). Concept analysis is a method of examining attributes or characteristics of nutrition problems for the purpose of defining the domain and boundary of each term. In this process, the definition, etiologies, and signs/symptoms of the term are proposed. ADA initiated this step by appointing rec- ognized leaders and award winners the task of identifying nutrition problems. Later, a 12-member NCP/Standardized Language Committee gathered input on the initial set of diagnostic terms from community, ambulatory, acute care, and long-term care practitioners and researchers. The results of this work, the labeling of nutrition diagnostic terms, was published (6), and annual updates $(7,8)$ were made as terminology was identified for the remaining steps in the $\mathrm{NCP}$ - assessment, intervention, and monitoring and evaluation.

\section{Validation Refines the Standardized Language}

After the diagnostic terms are labeled, the next logical step in language development is to validate the language (9). Content validation is the process of testing the language to learn whether the diagnostic terms fulfill the intended purpose of identifying and labeling separate and distinct nutrition problems (10). In essence, validation of the content of nutrition diagnostic terms confirms or verifies the definition, related etiologies, and the signs/symptoms required to define the term and ensure the language is clear, explicit, and succinct for each term. Currently, one published study has been conducted to test the validity of the content of the diagnostic terms by using a convenience sample of RDs to test all IDNT diagnostic terms (11). Another study measured the reliability of use of the terms among RDs with different years of practice (12). Clearly, more validation studies are needed using nutrition experts with experience in providing patient care for each of the 60 diagnostic terms in the IDNT reference manual (1) to assure that the terms are accurate for labeling nutrition problems.

A validated standardized language provides the benefit of allowing RDs to differentiate one diagnostic term from another $(13,14)$. RDs identify a nutrition diagnosis by observing the signs and symptoms that demonstrate its presence in a patient along with the underlying cause, the etiology. Signs/symptoms of a diagnostic term must occur in a cluster in a sufficient number of cases to be included in the diagnostic term and these sets of highly reliable clues provide accuracy in diagnosing. For example, the diagnostic terms involuntary weight loss and inadequate energy intake require validated clusters of signs and symptoms within each diagnosis to allow the RD to distinguish between the diagnoses. Is each diagnostic term a separate and distinct concept? The ability of RDs and DTRs to discern between diagnostic terms provides for accuracy and consistency in use of the standardized language. Accuracy in diagnosing is required for determining what evidence-based interventions are needed and what outcomes can be expected. The validation of the diagnostic terms may possibly disclose overlap of some terms.

Another benefit of validating the standardized language is explicating or defining the meanings of the signs/symptoms for proper measurement and use by RDs. Definitions of signs/symptoms and related etiologies of the term are instructions for what will be observed and how it will be observed. Operational definitions are needed to provide the bridge between incidental observation and scientific validation (15) and make it possible to replicate studies and relate findings across studies. For example, the signs/symptoms 


\begin{tabular}{|c|c|c|}
\hline $\begin{array}{l}\text { Steps for development } \\
\text { of diagnostic terms }\end{array}$ & Methodology & Outcome \\
\hline $\begin{array}{l}\text { 1. Identifying diagnostic } \\
\text { terms }\end{array}$ & $\begin{array}{l}\text { Concept analysis using exhaustive } \\
\text { literature review and experts }\end{array}$ & $\begin{array}{l}\text { Nutrition problems are described by defining an operational definition } \\
\text { (definition), antecedents (etiology), and attributes or consequences } \\
\text { (signs/symptoms) } \\
\text { - Differentiation of one nutrition problem from a similar or related } \\
\text { problem } \\
\text { Distinguish between defining attributes and irrelevant attributes of } \\
\text { nutrition problems } \\
\text { - Compiled comprehensive list of etiologies and signs/symptoms for } \\
\text { validation testing }\end{array}$ \\
\hline \multicolumn{3}{|l|}{$\begin{array}{l}\text { 2. Validating content of } \\
\text { diagnostic terms }\end{array}$} \\
\hline a. Expert validation & $\begin{array}{l}\text { Diagnostic Content Validation Model. } \\
\text { Interrater agreement between } \\
\text { experts in the nutrition problem } \\
\text { for scientific rigor. }\end{array}$ & $\begin{array}{l}\text { - Clear observable phenomena of consistent categories of knowledge } \\
\text { Definition, etiologies, and signs/symptoms clearly expressed or } \\
\text { defined } \\
\text { - Relevant shorter list of defining signs/symptoms and related } \\
\text { etiologies established } \\
\text { - Accuracy of diagnosing enhanced with limited and valid } \\
\text { signs/symptoms and related etiologies } \\
\text { - Terms are useful to informed registered dietitian }\end{array}$ \\
\hline b. Clinical validation & $\begin{array}{l}\text { Clinical Diagnosis Validation Model. } \\
\text { Interrater independent agreement } \\
\text { between registered dietitians of } \\
\text { observed presence of the signs/ } \\
\text { symptoms and related etiologies } \\
\text { within patients having the } \\
\text { diagnosis. }\end{array}$ & $\begin{array}{l}\text { Diagnostic terms, etiologies, and signs/symptoms exist in patients } \\
\text { - Validated terms available for evidence-based research and outcome } \\
\text { studies }\end{array}$ \\
\hline
\end{tabular}

Figure 1. Development and refinement of the American Dietetic Association's standardized language diagnostic terms. ${ }^{a}$ Fehring RJ. The Fehring model. In Carroll-Johnson RM, ed. Classification of Nursing Diagnoses: Proceedings of the Tenth Conference. Philadelphia, PA: Lippincott; 1994:55-62 (19).

of early satiety and poor intake listed in the standardized language may have different meanings among RDs and DTRs. If these are described as "stops eating within five minutes" and "eats less than 50\% offered" they have clearer meaning. The evidence or results of the validation are strengthened when meanings are explicit; therefore, validating the standardized language requires operational definitions of all items.

\section{Validation Models for Diagnostic Terms}

In the early 1980 s, methodologies for validating nursing diagnoses appeared in the literature, with these methods still used in their research today $(16,17)$. Validation of nutrition diagnostic terms should replicate the scientific rigor and models used in nursing validation studies to refine the language (Figure 1). The models allow comparisons between studies of the same language when one term is rated by
RDs in different practice settings or patient populations. Validation uses expert and clinical testing in two separate phases (Figure 1, Step 2a and 2b). In the expert validation phase (Figure 1, Step 2a), nutrition experts analyze the content of the term. Experts use fewer cues or signs/ symptoms when compared with novices to derive a correct diagnosis (18). To validate content of the term, the relevance, specificity, representatives, and clarity of the diagnosis is rated among the experts using a quantitative Likert-type scale in the Diagnostic Content Validation Model (19). A weighted response for each item is calculated to arrive at a mean score. Using the mean score, items are classified into major, minor, or irrelevant characteristics. The irrelevant etiologies and signs/symptoms are removed. A reduction in the number of signs/symptoms needed to identify a diagnosis has been an outcome of nursing diagnosis language validation studies (20, $21)$. Conceptual and succinct signs/symp- toms are more easily remembered than a longer list of less-specific parameters. The possible reduction in the number of defining signs/symptoms and related etiologies would make the diagnostic terms easier to use by RDs and DTRs.

Content validation by expert RDs provides evidence that the group thinks a certain way. However, there are no assurances that their judgment represents real-world phenomena. In the second phase of content validation (Figure 1, Step 2b), the diagnoses are studied using the Clinical Diagnostic Validation Model (19) in the clinical setting to provide a total picture of content validity. Independent clinicians observe and rate the etiologies and signs/symptoms in patients who are prediagnosed by a clinical expert other than the observers. The same scoring method of the Diagnostic Content Validation Model is used to obtain major, minor, and nonrelevant characteristics. The validated language is then available for IDNT revisions and future re- 
search studies that collect and measure nutrition care outcomes captured from electronic health care records. This research is vital to inform evidence-based practice (22), to improve quality of care, and to facilitate reimbursement of nutrition services $(23,24)$.

\section{Future Direction}

Diagnostic terms may be validated using nutrition experts who are members of dietetic practice groups and board-certified specialists who commonly see the nutrition problems in their practice setting. By involving RDs in these validation studies, the exposure to and adoption of the standardized language may increase, as a recent ADA survey of the dietetics profession revealed that less than one third were familiar with ADA's standardized language initiative and only $16 \%$ use the nutrition diagnostic terms (25). The IDNT should continue to be used while researchers and practitioners work together to validate the language, and it is likely that additional diagnostic terms may be conceptualized as the field of dietetics advances. Refining the standardized language through validation studies is both useful and meaningful to the dietetics profession. A validated language will facilitate documentation of nutrition care. In turn this will make it possible to collect the evidence needed to show the impact of nutrition services on patient outcomes.

Acknowledgments - This manuscript is a contribution of the University of Nebraska Agricultural Research Division. This manuscript was supported in part through the American Dietetic Association and the Hatch Act.

\section{References}

1. American Dietetic Association. International Dietetics and Nutrition Terminology (IDNT) Reference Manual. 2nd ed. Chicago, IL: American Dietetic Association; 2009.

2. Institute of Medicine, Crossing the Quality Chasm: A New Health System for the 21st Century. The National Academies Press website: http://books.nap.edu/html/quality chasm/reportbrief.pdf Published March 2001; accessed May 5, 2009.

3. N. Hakel-Smith, N. M. Lewis, and K. M. Eskridge, Orientation to nutrition care process standards improves nutrition care documentation by nutrition practitioners, $J \mathrm{Am}$ Diet Assoc 105 (2005), pp. 1582-1589.

4. Writing Group of the Nutrition Care Pro-
cess/Standardized Language Committee, Nutrition care process and model part I: The 2008 update, J Am Diet Assoc 108 (2008), pp. 1113-1117.

5. Writing Group of the Nutrition Care Process/Standardized Language Committee, Nutrition care process part II: Using the International Dietetics and Nutrition Terminology to document the nutrition care process, J Am Diet Assoc 108 (2008), pp. 1287-1293.

6. American Dietetic Association. Nutrition Diagnosis: A Critical Step in the Nutrition Care Process. Chicago, IL: American Dietetic Association; 2006.

7. American Dietetic Association. Nutrition Diagnosis and Intervention: Standardized Language for the Nutrition Care Process. Chicago, IL: American Dietetic Association; 2007.

8. American Dietetic Association. International Dietetics and Nutrition Terminology (IDNT) Reference Manual. 1st ed. Chicago, IL: American Dietetic Association; 2008.

9. A. M. Hubley and B. D. Zumbo, A dialectic on validity: Where we have been and where we are going, J Gen Psychol 123 (1996), pp. 207-215.

10. S. N. Haynes, D.C.S. Richard, and E. S. Kubany, Content validity in psychological assessment; A functional approach to concepts and methods, Psychological Assessment 7 (1995), pp. 238-247.

11. E. Enrione, Content validation of nutrition diagnosis, Top Clin Nutr 23 (2008), pp. 306-319.

12. P. J. Charney, J. K. O’Sullivan Maillet, R. Touger-Decker, P. Splett, E. Meyers, and S. Haque, Reliability of nutrition diagnostic labels when used by registered dietitians at three levels of practice, J Am Diet Assoc 106:8 (suppl) (2006), p. A12.

13. L. O. Walker and K. C. Avant, Strategies for Theory Construction in Nursing (3rd ed.), Appleton and Lange, Norwalk, CT (1995).

14. B. L. Rodgers, Concept analysis: An evolutionary view. In: B.L. Rodgers and K.A. Knafl, Editors, Concept Development in Nursing: Foundations, Techniques, and Applications. (2nd ed.), WB Saunders, Philadelphia, PA (2000), pp. 77-102.

15. J. Grant and M. Kinney, The need for operational definitions for defining characteristics, Nurs Diagn 2 (1991), pp. 181-185.

16. G. G. Whitley, Processes and methodologies for research validation of nursing diagnoses, Nurs Diagn 10 (1999), pp. 5-14.

17. L. M.Hoskins, How to do a validation study. In: M. Rantz \& P. Lemone, eds., Classification of Nursing Diagnoses: Proceedings of the Twelfth Conference. Glendale, CA: CINAHL1997:79-86.

18. P. Benner, From Novice to Expert, AdisonWesley, Menlo Park, CA (1984).

19. R. J. Fehring, The Fehring model. In: R. M. Carroll-Johnson, Editor, Classification of Nursing Diagnoses: Proceedings of the Tenth Con- ference, Lippincott, Philadelphia, PA (1994), pp. 55-62.

20. N. Oliveira, T. Chianca, and G. H. Rassool, A validation study of the nursing diagnosis anxiety in Brazil, In J Nurs Terminol Classif 19 (2008), pp. 102-110.

21. E. V. Carmona and M.H.B.M. Lopes, Content validation of parental role conflict in the neonatal intensive care unit, In J Nurs Terminol Classif 17 (2006), pp. 3-9.

22. American Dietetic Association House of Delegate, Fall 2009 mega issues: Evidencebased practice and health reform. American Dietetic Association website: http: / / www. eatright.org/HODMegaIssues ; accessed August 27, 2009.

23. N. Hakel-Smith and N. M. Lewis, A standardized nutrition care process and language are essential components of a conceptual model to guide and document nutrition care and patient outcomes, J Am Diet Assoc 104 (2004), pp. 1878-1884.

24. K. Sandrick, Is nutrition diagnosing a critical step in the nutrition care process?, $\mathrm{J} \mathrm{Am}$ Diet Assoc 102 (2002), pp. 427-431.

25. E. J. Ayres and L. B. Hoggle, ADA nutrition informatics member survey: Results and future steps, J Am Diet Assoc 108 (2008), pp. 1822-1826.

\section{Standardized Language Resources and Updates}

Take advantage of the following resources and periodic updates on standardized language available from the ADA:

ADA Members: $\underline{\text { http: //www. eatright. }}$ org $/$ Members $/$ content. aspx?id= 5477

Health Professionals: http://www. eatright.org/HealthProfessionals/ content.aspx?id $=7077$

- Nutrition Care Process SNAPshots outlining the standardized language in the four steps of the Nutrition Care Process.

- Helpful toolkits for applying the $\mathrm{Nu}$ trition Care Process/Standardized Language (NCP/SL) in the neonatal intensive care unit setting and longterm care setting and for establishing electronic records using the NCP/SL terminology.

- Supplemental material and references for the International Dietetics Nutrition Terminology Reference Manual, including procedures for submitting standardized language changes.

- Research opportunities for all ADA members to contribute toward developing the terms in the fourth step of the Nutrition Care Process-monitoring and evaluation. 